\title{
Role of mean fetal kidney length as an additional parameter in late trimester for accurate estimation of gestational age relative to other biometrics indices
}

\author{
Shalini Sahay ${ }^{1 *}$, Manju Sharma ${ }^{2}$, Devendra Kumar ${ }^{3}$, Bhawar Singh Meena ${ }^{4}$
}

\author{
${ }^{1}$ Final Year Resident Doctor, SMS Medical College, Jaipur, Rajasthan, India \\ ${ }^{2}$ Department of Obstetrics and Gynecology, SMS Medical College and Attached Hospital, Jaipur, Rajasthan, India \\ ${ }^{3}$ Department of Radiodiagnosis, JNU Medical College, Jaipur, Rajasthan, India \\ ${ }^{4}$ Department of Obstetrics and Gynecology, Mahila Chikitsalya, SMS Medical College, Jaipur, Rajasthan, India
}

Received: 24 June 2020

Accepted: 31 July 2020

\section{*Correspondence:}

Dr. Shalini Sahay,

E-mail: shalinisahay45@gmail.com

Copyright: $(\odot$ the author(s), publisher and licensee Medip Academy. This is an open-access article distributed under the terms of the Creative Commons Attribution Non-Commercial License, which permits unrestricted non-commercial use, distribution, and reproduction in any medium, provided the original work is properly cited.

\begin{abstract}
Background: As biometric indices are difficult to obtain or show gross discrepancies with each other or with gestational age in the late trimester, so for accurate dating additional parameter is required. Fetal kidney length is easy to measure and appear reliable in previous studies.

Methods: Well dated 121 antenatal women from 28 to 40 weeks of gestation with no obstetric or medical risk factors were recruited and kidney length is assessed in longitudinal scan and maximum length is taken. fetal kidney length derived gestational age compared with other biometrics indices gestational age.

Results: Mean kidney length showed significant correlation $(r=0.899, p<0.001$ value) with increasing gestational age. Mean kidney length dated pregnancy within \pm 8.5 days.

Conclusions: Fetal kidney length measurement correlated well with other routinely used parameters for the estimation of gestational age and can be used as an accurate parameter to date pregnancy in the late trimester.
\end{abstract}

Keywords: Gestational age, Late trimester, Mean kidney length

\section{INTRODUCTION}

Accurate dating of pregnancy is critically important for pregnancy management from the first trimester to delivery and is particularly necessary for determining viability in premature labor and post-dates deliveries. ${ }^{1}$ The NMR is 28 per 1000 live births in 2013. A systematic analysis of global, regional, national causes of child mortality in 2013 identified preterm birth complications and infections to be the two major causes of neonatal deaths in India. ${ }^{2}$ It is particularly important in high-risk pregnancies (severe preeclampsia, chronic hypertension, severe IUGR, central placenta previa, sensitized Rh-negative mother, etc) where in some cases early termination may become necessary and prerequisite to interpret certain tests (amniotic fluid assay, serum assay, chorionic villus sampling) and to plan the timing of various forms of fetal therapy. ${ }^{3}$

The estimated date of delivery (EDD) commonly known as 'due date' has traditionally been calculated from this by adding 280 days to the LMP date, or through Naegele's rule: subtracting 3 from the month and adding 7 days. this practice assumes a regular menstrual cycle of 28 days, with ovulation occurring on the $14^{\text {th }}$ day after the beginning of the menstrual cycle. ${ }^{4}$ So, this method of dating a pregnancy is inaccurate where there is not a reliable recollection of LMP, or if menstrual cycles are short, long, or irregular. the certainty of LMP has been reported as low as $32 \% .^{5}$ the estimated date of delivery calculation based on last menstrual period has its own set of limitations leading to false calculations like vague 
menstrual history, pregnancy during lactational amenorrhea, first trimester bleeding per vagina. ${ }^{6}$

The development of diagnostic ultrasound has opened new possibilities for reliable assessment of dating. GA can be estimated in the first trimester by ultrasonic measurement of diameter and volume of gestational sac as well as crown-rump length (CRL) (Bailey et al, Sahota et al, Karki et al, Lobo et al). Also, other biometric indices such as fetal biparietal diameter (BPD), femur length (FL) trans-cerebellar diameter (TCD), clavicle length (CL), foot length, and head circumference (HC) are used for GA estimation during different pregnancy trimesters Lobo et al. ${ }^{7}$ Most of these methods can predict gestational age with accuracy. However, these methods are not reliable in late trimester of pregnancy. Even the composite gestational age prediction in the third trimester does not give with great accuracy the actual gestational age, taking into consideration the discrepancies of late trimester scan and the possibility of growth retardation. ${ }^{8}$

Cohen et al conclude that kidney length correlates well with gestational age. Their conclusions agree with those of this study that kidney length could be used in the estimation of gestational age in pregnancies where dates are uncertain and the women present late for ultrasound biometry dating. ${ }^{9}$

Konje et al concludes that kidney length is a more accurate method of determining gestational age than the fetal biometric indices of biparietal diameter, head circumference, femur length and abdominal circumference between 24- and 38-weeks' gestation. When combined with biparietal diameter, head circumference, femur length, the precision of dating is improved by 2 days. ${ }^{10}$

Recent studies show that it is the most accurate single parameter for estimating gestational age than other biometric indices in late $2^{\text {nd }}$ and $3^{\text {rd }}$ trimester. $^{8}$

In this longitudinal study, authors are going to compare mean fetal renal length in the estimation of gestational age and their correlation with other sonography measured biometrics indices.

\section{METHODS}

Present study is hospital-based and cross-sectional study to be conducted in the department of obstetrics and gynecology, SMS Medical College and Hospitals, Jaipur from April 2018 onwards for one year or till the desired sample size is reached for data collection and two months for data analysis and compilation.

Fetal kidney length was compared with gestational age derived from LMP and Cohen et al nomogram or firsttrimester scan date if LMP or actual delivery date is not available. Fetal kidney length also compared with other studies i.e., Sagi et al, Kansaria et al, Bertagnoli et al, Ahmedi et al, and Chatterjee et al. ${ }^{8,9,11,12,14}$

\section{Inclusion criteria}

All women with singleton live pregnancy in their third trimester and willing to participate in the study. Women who are sure of their LMP and having regular periods were included in this study.

\section{Exclusion criteria}

Exclusion criteria of this study were suspected IUGR fetus, anomalous fetus, women with associated medical disorders (DM, HT, and thyroid dysfunction).

Institutional review board and ethical committee approval were taken before the study.

The study would comprise of pregnant women attending ANC clinic in Mahila Chikitsalya, SMS Medical College, Jaipur. The Sample size is calculated at $95 \%$ confidence levels assuming a standard deviation of $56 \mathrm{~mm}$ at 36 weeks gestational age, mean kidney length reference as found in seed article. At the absolute allowable error (precision) of $0.1 \mathrm{~mm}$ in kidney length, 121 patients are required as a sample size for study purposes.

\section{Method of collection of data}

Routine third-trimester pregnant patients attending to the department of obstetrics and gynecology in Mahila Chikitsalya hospital associated with SMS Medical College, Jaipur, Rajasthan, India were study and follows. the same patient will be evaluated as per history, general physical examination, and routine antenatal investigation. Following this using third-trimester ultrasonography, mean fetal kidney length along with fetal head circumference, femur length, abdominal circumference, and biparietal diameter will be measured. gestational age calculated from mean kidney length using nomogram by Cohen et al and from other biometrics indices using by Hadlock et al. these values are then compared with actual dates taken as a standard. USG assessment was done on machine of frequency probe.

\section{Statistical analysis}

Data was analyzed for the statistical significance using the intraclass correlation coefficient (r) significance found by student t-test. A p-value of $<0.05$ considered significant. Linear and multiple regression equations were formulated.

\section{RESULTS}

A total number of 121 patient was selected for the study. Maximum kidney length is measured in a longitudinal scan of each kidney then mean kidney length is used to calculate the gestational age. The kidney which is 
proximal to the transducer was measured (Figure 1 and Figure 2).

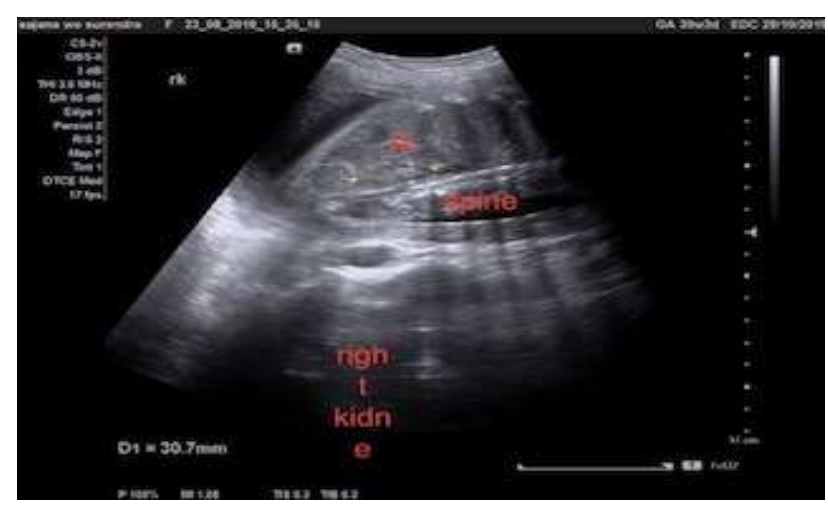

Figure 1: Right kidney length measured in longitudinal scan.

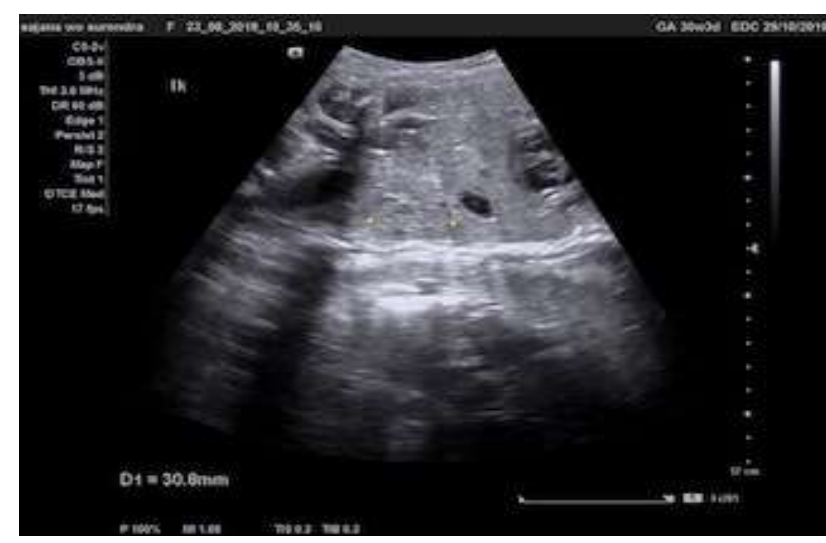

Figure 2: Left kidney length measured in longitudinal scan.

Similarly, biometric indices BPD, FL, and AC are measured then their corresponding clinical gestational age is calculated and compared with gestational age by fetal kidney length.

The cases were in the age group of 18 to 37 years maximum number of cases are in middle age group (2029 years) (Table 1$)$. And minimal in the elderly age group (>35 years).

Table 1: Frequency distribution of the cases according to their age in years.

\begin{tabular}{|lll|}
\hline Age distribution & No. of cases & Percentage \\
\hline <19 years & 4 & 3.3 \\
\hline $\mathbf{1 9 - 2 9}$ years & 94 & 77.68 \\
\hline $\mathbf{3 0 - 3 4}$ years & 21 & 17.35 \\
\hline$>$ 35 years & 2 & 1.6 \\
\hline
\end{tabular}

A maximum number of cases i.e., 17 (14\%) of women belonged to 39 weeks of gestation. The minimal number of cases belong to 41 weeks $1(0.008 \%)$. The number of cases in each gestational age was randomly selected.
It was observed that mean fetal kidney length increased linearly with an increase in gestational age. Mean kidney length is $27.33 \pm 1.53 \mathrm{~mm}$ at 28 weeks and $41 \pm 1.00 \mathrm{~mm}$ at 42 weeks of gestational age (Table 2).

Table 2: Mean fetal kidney length at various gestational ages.

\begin{tabular}{|llll|}
\hline $\begin{array}{l}\text { Gestational } \\
\text { age in weeks }\end{array}$ & $\begin{array}{l}\text { Mean fetal } \\
\text { kidney length }\end{array}$ & SD & C.I. \\
\hline $\mathbf{2 8}$ & 27.33 & 1.53 & -3.128 to 4.461 \\
\hline $\mathbf{2 9}$ & 30.20 & 0.84 & -2.239 to -0.1611 \\
\hline $\mathbf{3 0}$ & 30.88 & 1.36 & -2.009 to 0.2588 \\
\hline $\mathbf{3 1}$ & 31.33 & 1.37 & -1.767 to 1.1 \\
\hline $\mathbf{3 2}$ & 33.40 & 0.89 & -2.511 to -0.2894 \\
\hline $\mathbf{3 3}$ & 34.90 & 0.99 & -2.611 to -1.189 \\
\hline $\mathbf{3 4}$ & 35.00 & 1.94 & -2.489 to 0.4885 \\
\hline $\mathbf{3 5}$ & 35.45 & 2.11 & -1.875 to 0.9663 \\
\hline $\mathbf{3 6}$ & 35.14 & 1.35 & -0.3869 to 2.101 \\
\hline $\mathbf{3 7}$ & 37.00 & 1.10 & -1.15 to 1.15 \\
\hline $\mathbf{3 8}$ & 39.70 & 2.36 & -3.388 to -0.0122 \\
\hline $\mathbf{3 9}$ & 39.59 & 2.29 & -1.767 to 0.5907 \\
\hline $\mathbf{4 0}$ & 41.00 & 1.69 & -2.413 to 0.4131 \\
\hline $\mathbf{4 1}$ & 43.00 & 0.00 & \\
\hline $\mathbf{4 2}$ & 41.00 & 1.00 & -1.484 to 3.484 \\
\hline
\end{tabular}

Mean fetal kidney length has almost corresponded with gestational age. In this study, minimal fetal kidney length was $27.33 \mathrm{~mm}$ at 28 weeks and maximum length $43 \mathrm{~mm}$ at 41 weeks Table 2.

The correlation for CGA vs BPD, AC, and FL was significant (correlation coefficient r: 0.846, 0.859, 0.899 respectively). the correlation was best for CGA versus FKL ( $r=0.935, p<0.001$ value, Table 3$)$.

Table 3: The association between CGA and fetal kidney length derived gestational age.

\begin{tabular}{|lll|}
\hline $\begin{array}{l}\text { Karl Pearson } \\
\text { correlation }\end{array}$ & 0.935 & $\mathrm{P}<0.001$ \\
\hline
\end{tabular}

And least for CGA vs BPD (r: 0.846, Table 4).

Table 4: The association between CGA and BPD derived gestational age.

\begin{tabular}{|lll|}
\hline & CGA versus BPD GA & P value \\
\hline $\begin{array}{l}\text { Karl Pearson } \\
\text { correlation }\end{array}$ & 0.846 & $\mathrm{P}<0.001$ \\
\hline
\end{tabular}

All the correlations were statistically significant.

In this study, it has shown that fetal kidney length dates pregnancy with the accuracy of \pm 8.5 days compares to BPD \pm 10.5 days, FL by \pm 10.5 days, AC by \pm 9.5 days. Hense proves that fetal kidney length can be used to date 
the pregnancy in the last trimester in addition to other parameters.

\section{DISCUSSION}

This study was done to find out that fetal kidney length can be used as a biometric parameter in late trimester in the Indian population and to measure the normal length of fetal kidneys sonographically during the late trimester of pregnancies in all the cases of this study. The range of mean kidney length was 27.33 at 28 weeks and maximum at 41 weeks i.e., $43 \mathrm{~mm}$. In this study, we found that mean fetal kidney length almost corresponds with gestational age that is it is 27.33 at 28 weeks, 30.88 at 30 weeks, and 39.59 at 39 weeks. This study is also found that mean kidney length is linearly increasing with each gestational age, and there were significant differences in mean kidney length that corresponds to gestational weeks. Accordingly, standard deviation and 95\% confidence interval is calculated (Table 5).

This study values closely correlate with Sagi et al study who assessed fetal renal anatomy in 660 normal fetuses, establishing fetal gestational age, as well as the assessment of normal renal morphology in routine obstetric ultrasound assessment (Table 6). ${ }^{11}$

Table 5: Mean and standard deviation of gestational age derived from various indices compared with clinical gestational age.

\begin{tabular}{|lllllllll|}
\hline Gestational age in weeks & BPD & & AC & & FL & & KL \\
& Mean & SD & Mean & SD & Mean & SD & Mean & SD \\
\hline $\mathbf{2 8}$ & 69.67 & 1.53 & 231.67 & 13.65 & 69.67 & 1.53 & 27.33 & 1.53 \\
\hline $\mathbf{2 9}$ & 73.40 & 3.78 & 242.00 & 19.40 & 73.40 & 3.78 & 30.20 & 0.84 \\
\hline $\mathbf{3 0}$ & 76.00 & 3.85 & 265.88 & 10.38 & 76.00 & 3.85 & 30.88 & 1.36 \\
\hline $\mathbf{3 1}$ & 79.17 & 4.67 & 263.00 & 19.91 & 79.17 & 4.67 & 31.33 & 1.37 \\
\hline $\mathbf{3 2}$ & 77.80 & 3.27 & 282.40 & 16.32 & 77.80 & 3.27 & 33.40 & 0.89 \\
\hline $\mathbf{3 3}$ & 79.90 & 2.02 & 288.80 & 13.88 & 79.90 & 2.02 & 34.90 & 0.99 \\
\hline $\mathbf{3 4}$ & 82.67 & 3.84 & 300.22 & 19.89 & 82.67 & 3.84 & 35.00 & 1.94 \\
\hline $\mathbf{3 5}$ & 85.36 & 3.07 & 315.64 & 13.21 & 85.36 & 3.07 & 35.45 & 2.11 \\
\hline $\mathbf{3 6}$ & 84.29 & 2.43 & 306.14 & 11.94 & 84.29 & 2.43 & 35.14 & 1.35 \\
\hline $\mathbf{3 7}$ & 86.83 & 2.56 & 309.83 & 10.57 & 86.83 & 2.56 & 37.00 & 1.10 \\
\hline $\mathbf{3 8}$ & 86.20 & 4.13 & 322.90 & 21.34 & 86.20 & 4.13 & 39.70 & 2.36 \\
\hline $\mathbf{3 9}$ & 86.65 & 5.02 & 317.12 & 25.26 & 86.65 & 5.02 & 39.59 & 2.29 \\
\hline $\mathbf{4 0}$ & 88.00 & 3.42 & 331.38 & 15.72 & 88.00 & 3.42 & 41.00 & 1.69 \\
\hline $\mathbf{4 1}$ & 89.00 & 0.00 & 344.00 & 0.00 & 89.00 & 0.00 & 43.00 & 0.00 \\
\hline
\end{tabular}

Table 6: Comparison between the mean fetal kidney length of the study with that of the other studies.

\begin{tabular}{|lllllll|}
\hline $\begin{array}{l}\text { Gestational } \\
\text { age in weeks }\end{array}$ & $\begin{array}{l}\text { In this } \\
\text { present } \\
\text { study }\end{array}$ & Sagi et al ${ }^{11}$ & Kansaria et al ${ }^{\mathbf{8}}$ & Cohen et al $^{\mathbf{9}}$ & Bertagnoli et al $^{14}$ & Ahmedi et al \\
\hline $\mathbf{2 8}$ & 27.33 & 27.8 & 26.9 & 34 & 27.2 & 32.27 \\
\hline $\mathbf{3 0}$ & 30.88 & 30.5 & 29 & 38 & 28.8 & 35.23 \\
\hline $\mathbf{3 2}$ & 33.40 & 33.3 & 30.8 & 41 & 30.4 & 37.41 \\
\hline $\mathbf{3 4}$ & 35.0 & 36.0 & 32.5 & 42 & 34.0 & 39.70 \\
\hline $\mathbf{3 6}$ & 35.14 & 38.2 & 34.2 & 42 & 34.0 & 40.81 \\
\hline $\mathbf{3 8}$ & 39.7 & 40.3 & 36.2 & 44 & 36.0 & 42.45 \\
\hline
\end{tabular}

Table 7: Regression equation application between FKL/BPD/AC/FL versus CGA.

\begin{tabular}{|llllllll|}
\hline FKL & Intercept estimate & Intercept SE & Slope estimate & Slope SE & P value & $\mathbf{R}^{2}$ & Sep (days) \\
\hline Present study & 2.6 & 0.12 & 0.11 & 0.036 & 0.001 & 87 & 8.54 \\
\hline Kansaria et al $^{8}$ & 2.9 & 0.42 & 0.83 & 0.014 & $<0.0001$ & 97 & 9.17 \\
\hline Konje et al $^{10}$ & 3.8 & 0.38 & 0.85 & 0.012 & $<0.0001$ & 90 & 10.29 \\
\hline Saxena et al $^{15}$ & 3.0 & 0.34 & 0.99 & 0.099 & $<0.0001$ & 98 & 2.81 \\
\hline
\end{tabular}


Indian studies closely matched from our studies are Kansaria et al (28 to 30 weeks), studied 70 women of regular menstrual cycle, fetal biometry is assessed at 2 weekly intervals between 22 weeks and 38 weeks of gestation was performed to measure fetal kidney parameters and BPD, FL, AC, head circumference (HC). ${ }^{10}$ Study concludes that foetal kidney length grows at the rate of $1.7 \mathrm{~mm}$ fortnightly and pregnancies could be dated within 9.17 days. $^{8}$ Similarly, our study concludes that pregnancy is dated within \pm 8.5 days of the standard error of prediction by mean kidney length of the women having regular menstrual cycles. It is well correlated with 10.29 days in Konje study. ${ }^{10}$

This study also shows that compare to other biometric indices fetal kidney length is relatively more accurate as the standard error of prediction that gestational age can be calculated from fetal kidney length with a difference of \pm 8.5 days. it has shown that BPD dates pregnancy with the accuracy of \pm 10.5 days, FL by \pm 10.5 days, AC by \pm 9.5 days (Table 6 ).

Other Indian studies we suggest are Chatterjee et al (28 to 38 weeks) studied 100 pregnant women with known dates of different parity and ages for the period of one year (2015 to 2016) conclude that kidney length can be used as an individual parameter in estimating gestational age, especially in later trimesters, where biometric indices may not be much reliable. ${ }^{12}$

Similarly, Monalisa et al (28 to 31 weeks) studied 200 pregnant women with known dates of different parity and ages for the period of two years (2013 to 2015) conclude FKL can be combined with the other four biometric indices to give a fair estimation of gestational age. ${ }^{13}$ kidney length could predict gestational age with an accuracy \pm 9.048 days and predictability when combined with other biometric indices was \pm 8.299 days. ${ }^{13}$

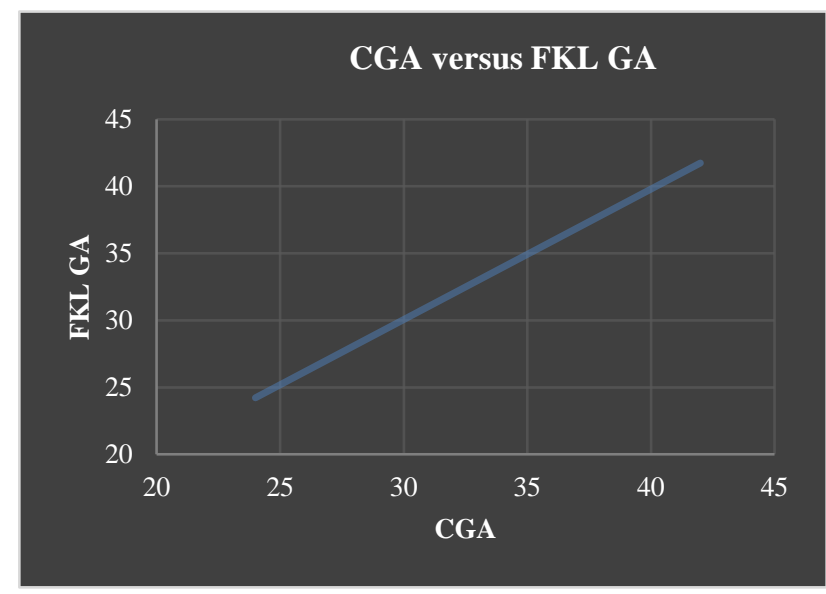

Figure 3: The correlation of $93.5 \%(r=0.935)$ between CGA GA and FKL in both trimesters (Konje et al 0.8824, Cohen et al 0.91, Chatterjee et al 989, Bardhan et al 0.99) and least for CGA versus BPD $(r=0.846)$.
Mean kidney length also correlates with Bertagnoli et al at 28 to 36 weeks. ${ }^{14}$ Who studied 280 pregnant women of 22 to 40 weeks gestations. The relationships of the A-P diameter and length to menstrual age were determined in cross-sectional and longitudinal studies of kidney growth. The results obtained confirmed that measurements of the fetal kidney can be used as an additional parameter in the routine assessment of fetal wellbeing and to rule out kidney malformations characterized by changes in kidney size. ${ }^{14}$

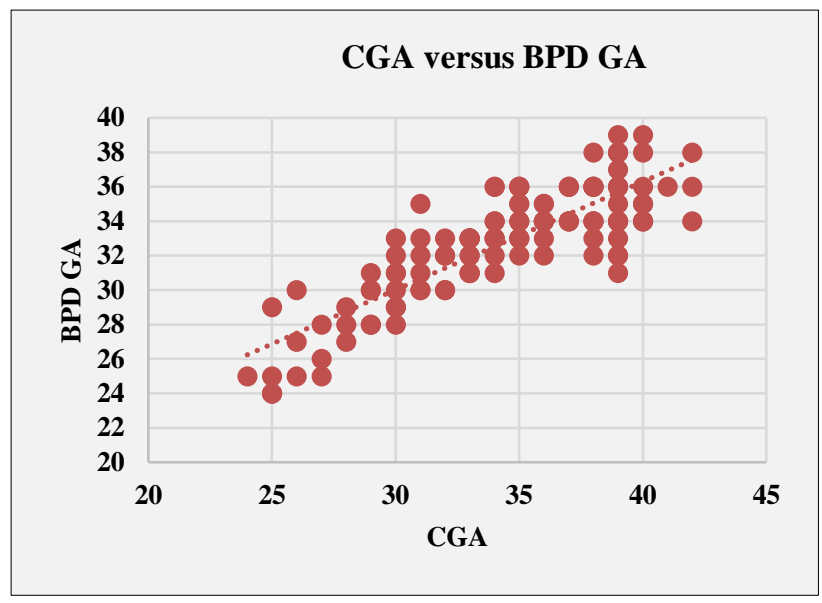

Figure 4: The correlation of $84.6 \%(r=0.846)$ between CGA GA and BPD in both trimesters. (Konje $r=0.792$, Bardhan J et al $r=0.99$ ).

Thus, this study suggests 30 weeks was $30.88 \pm 1.36 \mathrm{~mm}$, in Kansaria 29.03 $\pm 1.32 \mathrm{~mm}$, in Saxena et al. $29.67 \pm 0.51$ $\mathrm{mm}$, and Konje it is $30.9 \pm 3.2 \mathrm{~mm}$. In this study mean kidney length at 38 weeks was $39.7 \pm 2.36 \mathrm{~mm}$ in Kansaria $36.25 \pm 1.70 \mathrm{~mm}$, in Saxena et al, $37.54 \pm 0.54 \mathrm{~mm}$ and Konje study $40 \pm 2.4 \mathrm{~mm} .^{15}$

The correlation for CGA versus BPD, AC, and FL was almost similar (correlation coefficient $r=0.846,0.859$, 0.899 respectively). the correlation was best for CGA versus FKL ( $r=0.935, \mathrm{p}<0.001$ value, Figure 3 ).

All the correlations were statistically significant.

According to this study, fetal kidney length in $\mathrm{mm}$ are almost equal to the weeks at a particular gestational age with approx. \pm 8.5 days of the standard error of prediction. this is similar to study done by Bertagnoli et al, Sagi et al, Konje et al and shows their measurement is almost equal to our study.

\section{CONCLUSION}

The present study hence validates the recommendation that fetal kidney length can be used as an important sonographic parameter in late trimester for accurate prediction of fetal Gestational age in the Indian population. 
Funding: No funding sources

Conflict of interest: None declared

Ethical approval: The study was approved by the Institutional Ethics Committee

\section{REFERENCES}

1. Butt K, Fredericton NB, Lim K, Vancouver BC. Determination of gestational age by ultrasound. J Obstet Gynaecol Can. 2014;36(2):171-81.

2. Sankar MJ, Neogi SB, Sharma J, Chauhan M, Srivastava R, Prabhakar PK, et al. State of newborn health in India. J Perinatol. 2016;36(Suppl 3):S3-S8.

3. Kaul I, Menia V, Anand AK, Gupta R. Role of foetal kidney length in estimation of gestational age. JK Sci. 2012;14:65-9.

4. Naegele FC. Lehrbuch der Geburtshilfe fur Hebammen, $3^{\text {rd }}$ edn. Mohr, Heidelberg; 1836.

5. Geirsson RT, Busby-Earle RM. Certain dates may not provide a reliable estimate of gestational age. $\mathrm{Br}$ J Obstet Gynaecol. 1991;98:108-9.

6. Bardhan J, Ghosh SK, Sarkar KN, Sarkar M. Fetal kidney length as a parameter for gestational age determination and its comparative evaluation with other fetal biometric indices. IAIM. 2016;3(8):36-44.

7. Adam M, Tamboul J, Yousef M, Sulieman A. The normal fetal kidney measurement in in normal pregnant ladies. J Am Sci. 2013;9(12):794-7.

8. Kansaria JJ, Parulekar SV. Nomogram for foetal kidney length. Bombay Hospital J. 2009;51(2):15562.

9. Cohen HL, Cooper J, Eisenberg P, Mandel FS, Gross BR, Goldman MA, Barzel E, Rawlinson KF. Normal length of fetal kidneys: sonographic study in 397 obstetric patients. AJR. AJR Am J Roentgenol. 1991;157(3):545-8.

10. Konje JC, Abrams KR, Bell SC, Taylor DJ. Determination of gestational age after the $24^{\text {th }}$ week of gestation from fetal kidney length measurements. Ultra Obstet Gynecol. 2002;19(6):592-7.

11. Sagi J, Vagman I, David MP, Van Dongen LG, Goudie E, Butterworth A, et al. fetal kidney size related to gestational age. Gynecol Obstet Invest. 1987;23(1):1-4.

12. Chatterjee S, Yadav K, Prakash P, Shekhawat K. Foetal kidney length as a parameter for determination of gestational age in pregnancy by ultrasonography. Int $\mathbf{J}$ Reprod Contracept Obstet Gynecol. 2016;5(6):1949-52.

13. Peter M, Nayak AK, Giri PP, Jain MK. Fetal kidney length as a parameter for determination of gestational age from 20th week to term in healthy women with uncomplicated pregnancy. Int $\mathrm{J}$ Res Med Sci. 2017;5(5):1869-73.

14. Bertagnoli L, Lalatta F, Gallicchio R, Fantuzzi M, Rusca M, Zorzoli A, Deter RL. Quantitative characterization of the growth of the fetal kidney. Clin Ultrasound. 1983;11(7):349-56.

15. Saxena R, Saxena G, Joshi K, Yadav K. Foetal kidney length as a parameter for determination of gestational age in pregnancy by ultrasonography. J Med Res Prof. 2016;2(6):71-3.

Cite this article as: Sahay S, Sharma M, Kumar D, Meena BS. Role of mean fetal kidney length as an additional parameter in late trimester for accurate estimation of gestational age relative to other biometrics indices. Int J Reprod Contracept Obstet Gynecol 2020;9:3724-9. 